\title{
Retraction Note to: Changes in Bone and Calcium Metabolism Following Hip Fracture in Elderly Patients
}

\author{
Editorial Office of Osteoporosis International
}

Published online: 4 January 2021

(C) International Osteoporosis Foundation and National Osteoporosis Foundation 2020

Retraction Note to: Osteoporos Int (2001) 12:445-449.

https://doi.org/10.1007/s001980170088

The Editors-in-Chief have retracted this article [1]. Contrary to the statement in the article, Kurume University confirmed that the authors did not have ethical approval for this study.

We have been unable to contact M. Kaji, F. Higuchi, I. Yanagida, K. Oishi and K. Oizumi about this retraction. Y. Sato is deceased.

\section{Reference}

1. Sato Y, Kaji M, Higuchi F, Yanagida I, Oishi K, Oizumi K (2001) Changes in bone and calcium metabolism following hip fracture in elderly patients. Osteoporos Int 12:445-449. https://doi.org/10.1007/ s001980170088

Publisher's note Springer Nature remains neutral with regard to jurisdictional claims in published maps and institutional affiliations.

The online version of the original article can be found at https://doi.org/ $10.1007 /$ s001980170088

Editorial Office of Osteoporosis International

Osteoporosis International,

https://www.springer.com/journal/198 